\title{
ORIENTATION FABRICS IN LAKE ICE
}

\author{
By J. B. Lyons and R. E. Stroiber \\ (Department of Geology, Dartmouth College, Hanover, N.H.)
}

\begin{abstract}
AвSTRACт. Laboratory experiments and field observations permit an explanation of the varying crystallographic orientations observed in lake ice in terms of four factors: ( $\mathrm{I}$ ) coincidence of the plane of most rapid growth in ice (the basal plane) with the vector of thermal flux, (2) mechanical fragmentation of earlyformed dendrites and plates by winds above a critical velocity (approximately $2 \cdot 7 \mathrm{~m}$. $/ \mathrm{sec}$.), (3) the presence of a sufficiently thick layer of supercooled water to permit vertical crystal growth, and (4) the operation of geometric factors, first pointed out by Perey and Pounder, which result in the gradual elimination of the
flatter plates of growing ice by the steeper ones.
\end{abstract}

RÉsumé. Les expériences en laboratoire et les observations sur le terrain permettent une explication des orientations cristallographiques variables observées dans la glace de lac, à partir de 4 facteurs: (I) coïncidence du plan de croissance la plus rapide dans la glace (plan de base) avec le vecteur de flux thermique, (2) fragmentation mécanique des dendrites et plaques préalablement formées par des vents dépassant une vitesse critique (environ $2,7 \mathrm{~m} / \mathrm{sec}$ ), (3) présence d'une couche suffisamment épaisse d'eau surfondue pour permettre la croissance verticale du cristal, et (4) l'effet de facteurs géométriques mis en évidence pour la première fois par Perey et Pounder (1958), qui résulte, pour la glace croissante, en l'élimination graduelle des plaques les plus horizontales par celles qui sont plus inclinées.

ZuSAmmenFassung. Laborversuche und Feldbeobachtungen gestatten eine Erklärung für die unterschiedlichen kristallographischen Orientierungen, die in See-Eis beobachtet wurden, aus 4 bestimmenden Faktoren: (I) Koinzidenz der Ebene grössten Eiswachstums ("basal plane") mit dem Vektor des Wärmeüusses, (2) mechanische Zerstörung von Zapfen und Platten eines früheren Bildungsstadiums durch Winde über einer kritischen Geschwindigkeit (etwa 2,7 m/sec), (3) das Vorhandensein einer ausreichend dicken metrischer Faktoren, auf die erste vertikales Kristallwachstum erlaubt, und (4) die Wirksamkeit geometrischer Faktoren, auf die erstmals von Perey und Pounder (1958) hingewiesen wurde und die zum schrittweisen Abbau flacherer Platten des wachsenden Eises durch die steileren führt.

\section{INTRODUCTION}

Lake ice consists of an interlocking aggregate of columnar crystals which commonly increase both in size and complexity of grain shape with depth. Normally such ice has a preferred fabric, with horizontal or vertical $c$-axis orientation. Where both orientations occur near the surface, or where there is some randomness, there may be a progressive increase in horizontally oriented $c$-axes with depth (Ragle, 1962). The inverse relation is apparently unknown.

Crystallographic orientation is a significant strength parameter for melting lake ice. Because of the basal glide properties of ice, one would expect lake ice with horizontal $c$-axis orientation to have a lower ultimate strength under vertically directed stress than lake ice with other orientations. Nevertheless, significant differences are not detected in field tests conducted while the ice is at sub-freezing temperatures (Barnes, 196o). With the onset of melting, Tyndall figures and vapor bubbles develop and migrate rapidly along the vertically oriented basal planes of ice with horizontal $c$-axes (Barnes, I 960). Albedo is lowered, and the ice greatly weakened. If the $c$-axes are vertical, Tyndall figures are incapable of appreciable migration, nor can the vapor bubbles readily escape. Albedo is raised, and the ice strength tends to be preserved.

\section{Growth Rates in Ige Crystals}

An ideal anistropic crystal forming from a solution in which a thermal gradient has been established should have growth velocities proportional to thermal conductivity vectors of the crystal (cf. Saratovkin, 1959, p. I04). In ice, thermal conductivity, parallel to the $c$-axis is approximately 5 per cent greater than that parallel to the basal plane (Landauer and Plumb, 1956). Nevertheless, all determinations of growth rates of ice from solution (cf. Hillig, [1958], fig. I) have shown that the velocity of growth parallel to the basal plane may be as much as Ioo times more rapid than growth in the $c$-axis direction. Thermal conductivity, therefore, cannot be a significant parameter controlling ice growth rates or orientations. 


\section{Experimental Observations on Ice Orientation}

In undisturbed supercooled water (Devik, I942), ice growth is generally initiated by nucleation and rapid expansion of dendrites or needles along an $a$-axis. When an offshoot develops along a second $a$-axis, the resulting platelet floats. Expansion, coalescence, and eventual thickening of these plates explain the texture and orientation of "normal" lake ice.

The above explanation cannot hold for lake ice of horizontal $c$-axis orientation (Barnes, I960; Taylor, unpublished), nor for the case described by Owston (195I), where rain water was caught in a tarpaulin, and frozen; the resulting ice aggregate had all $c$-axes horizontal. Because heat loss in Owston's case was multidirectional, and in lakes is unidirectional, one must also conclude that the heat flow vector, like thermal conductivity, does not directly control ice orientation in nature.

Brill (1957) has grown ice with horizontal $c$-axis in the laboratory, using a shallow, wellinsulated container fitted with a bottom stirrer. Crystallization at the container walls was prevented by electric heating, and edge effects were thereby eliminated. More recently, Perey and Pounder (1958) grew ice in plastic containers so insulated that heat flux was vertical. They found that the fractional area, but not the relative number, of crystals with horizontal $c$-axis increased with depth.

We have repeated the Perey-Pounder experiments but have also varied the direction of heat flux, allowing the ice to solidify from the top, the bottom, or all sides simultaneously. Commercially grown ice was also studied as a check on the last experiment. As a last factor, we have added wind (provided by an electric fan). Reservoir water was used in all runs, and the ice crystallized in a cold room with $-\mathrm{IO}^{\circ} \mathrm{C}$. ambient temperature.

Artificial ice grown under conditions of upward vertical heat flux consists over most of the surface of an aggregate of coarse crystals with mean diameters up to $5 \mathrm{~cm}$., and a narrow perimeter in which the grain diameters are $0.5 \mathrm{~cm}$. or less. The coarse central crystals have vertical to sub-vertical $c$-axes, the peripheral crystals horizontal to sub-horizontal $c$-axes. At depth there are relatively more crystals with horizontal $c$-axes. The reason becomes apparent if one arrests the growth process. Shortly after surface crystallization has commenced, the entire column of water in the container achieves a temperature of $\pm 0.15^{\circ} \mathrm{C}$., as indicated by thermocouple measurements. Crystals at the perimeter of the block grow downward far more rapidly than the others, extending dendrites into the water bath and under the central (vertical $c$-axis) crystals. There is no new nucleation below the upper ice surface, and elimination of $c$-axis crystals with depth is due to a growth-geometric factor. Note, however, that edge effects are significant here, and natural conditions are not satisfactorily reproduced.

When ice is grown under conditions of all-sided or vertically downward heat flow a columnar ice aggregate results, as before. Except near the central upper surface of such blocks, crystals have their basal planes normal to the cooling surface. The general textural characteristics of such ice blocks are identical to those in metal castings, even to the development of the familiar globular texture at the center. In metals, however, the long direction of the columns is the vector of both maximum thermal conductivity and maximum growth velocity; in ice it is only the vector of maximum growth velocity.

Striking alterations in the normal orientation patterns of artificial ice are produced when a steady air stream is directed tangentially toward the surface of a water container so insulated that an upward heat flow has been established. At low wind velocities (e.g. $\mathrm{I} \cdot 5 \mathrm{~m}$./sec. or less) the only perceptible change in the crystallized ice is a decrease in grain diameter, to an average of $\mathrm{I} \mathrm{cm}$. or less at the surface. If the wind velocity is increased to $2.7 \mathrm{~m}$. $/ \mathrm{sec}$., the grain diameter is diminished still further to $0.15 \mathrm{~cm}$. or less, and the petrofabric diagram of all grains coarse enough to be optically identifiable shows sub-horizontal orientation of $c$-axes. As these crystals are traced downward, some enlarge and others are wedged out, for no obvious reason; at a depth of $10 \mathrm{~cm}$. their average diameter increases to $0.7 \mathrm{~cm}$. 
Discussion

Perey and Pounder (I958) have proposed that geometric arrangement of the rapidly growing basal planes of ice crystals is the fundamental control on lake ice crystal orientation (cf. Fig. I). This is partially correct; but does not explain (I) how a random orientation of ice nuclei may be set up, and (2) why intermediate orientations are relatively rare.
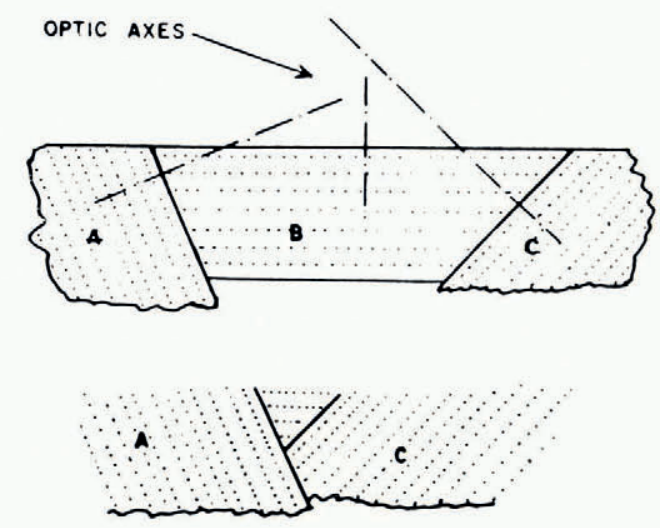

Fig. I. Mechanism proposed by Perey and Pounder (1958) to explain cutting-out of ice crystals with vertical c-axes with progressive thickening of an ice sheet. Dotted lines are the basal pales of the crystals. Reproduced by permission from Canadian Journal of Physics

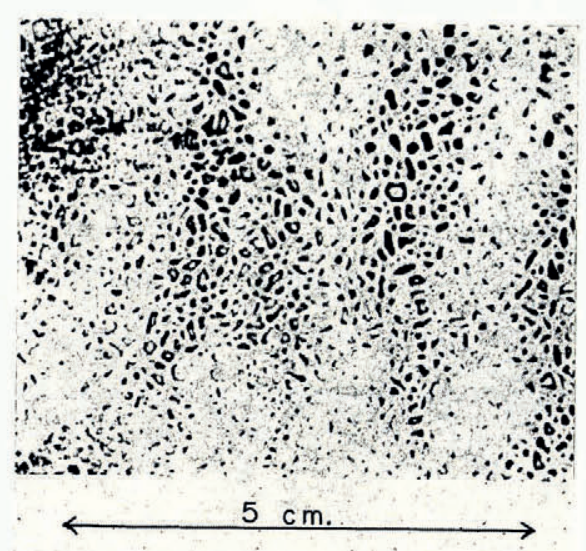

Fig. 2. Rubbing of brecciated upper surface of ice grown at wind velocity of $2.7 \mathrm{~m}$./ $/ \mathrm{sec}$.

Rubbings (Fig. 2) of the surface of wind-blown artificial ice suggest a rather simple explanation for obviating these difficulties. This surface, with its strikingly atypical grainboundary relations, results from fragmentation of thin early formed ice plates or dendrites. During incipient ice growth, jostling in the well stirred upper water surface (I) thickens the supercooled surface water layer, and (2) makes it progressively more difficult for flat dendrites or plates to persist. A mush of broken crystals accumulates; when this mush attains a thickness of a millimeter or so, a condition is reached in which further horizontal crystal growth is virtually impossible. Thus shards or intergranular crystals which rotate or nucleate in such a position that their basal planes are sub-vertical grow most rapidly immediately below the 
disturbed surface layer. At a few millimeters depth, this orientation becomes dominant by the operation of the geometric (or Perey-Pounder) factor. The development of a crystal mush in agitated water is therefore a crucial step in initiating horizontal $c$-axes orientation in the case described, and probably in most lakes.

A question not yet answered is why, in experiments carried out under conditions of vertical heat flux, perimeters of the ice blocks have horizontal $c$-axis orientations; or why, when heat flux is all-directional, the $c$-axes are sub-parallel to the container walls. The standard explanation for orientations in metal castings (i.e. preferential growth of nuclei favorably oriented with respect to heat flow vectors), probably applies here. The experiments themselves, however, have no natural applications or analogues to lake ice.

\section{Acknowledgements}

Laboratory and field investigations reported upon in this study were supported by the Geophysics Research Directorate, Air Force Cambridge Research Laboratories, Office of Aerospace Research. We are also indebted to Mr. George Fisher for excellent assistance in the laboratory.

MS. received 6 April $19^{62}$

\section{REFERENCES}

Barnes, D. F. 196o. Preliminary report on Lake Peters, Alaska, ice studies. Proceedings, second annual Arctic Planning Session, Geophysics Research Directorate, Air Force Cambridge Research Center, p. 102-09.

Brill, R. 1957. Structure of ice. U.S. Snow, Ice and Permafrost Research Establishment. Report 33.

Devik, O. 1942. Supercooling and ice formation in open waters. Geofysiske Publikasjoner, Vol. I3, No. 8, p. I-10.

Devik, O. I942. Supercooling and ice formation in open waters. Geofysiske Prendicular to the basal plane. (In Doremus, R. H., and others, ed. Growth and perfection of crystals: proceedings of an international conference on crystal growth held at R. H., and others, ed. Growth and perfection of crystals: proceedings of an international conference on . Now and Sons, Inc., p. 350-60.)

Landauer, J. K., and Plumb, H. 1956. Measurements on anisotropy of thermal conductivity of ice. U.S. Snow, Ice and Permafrost Research Establishment. Research Report 16.

Owston, P. G. I951. The crystallization of ice. Fournal of Glaciology, Vol. I, No. 10, p. 571-73.
Perey, F. G. J., and Pounder, E. R. 1958. Crystal orientation in ice sheets. Canadian Fournal of Physics, Vol. 36 ,

No. 4, p. 494-502.
Ragle, R. H. 1962 . Investigation of the formation of lake ice in a temperate climate. U.S. Cold Regions Research and Engineering Laboratory. Research Report 107.

Saratovkin, D. D. 1959. Dendritic crystallization. Second edition, revised and enlarged. Translated from Russian by f. E. S. Bradley. New York, Consultants Bureau, Inc.

Taylor, L. D. Unpublished. Ice petrofabrics of Angiussaq Lake, northwest Greenland. [M.A. thesis, Dartmouth College, r 958.] 